\title{
A Study of Changes in the Element Composition and Structure of Surfaces under Irradiation of Dense Xenon Gas (270 bar) by Y-Rays with a Maximum Energy of 10 $\mathrm{MeV}$
}

\author{
A. Yu. Didyk ${ }^{1}$, G. G. Gulbekian ${ }^{1}$, G. V. Mishinskiy ${ }^{1}$ and R.Wisniewski ${ }^{2}$ \\ 1. Joint Institute for Nuclear Research, Dubna 141980, Russia \\ 2. Warsaw University of Technology, Warsaw 02-672, Poland
}

\begin{abstract}
A high-pressure chamber filled with natural xenon (XeHPC) under initial pressure 270 bar was irradiated during 43 hours by braking $\gamma$-rays with a maximum energy of $10 \mathrm{MeV}$ at the MT-25 electron accelerator at an average beam intensity of 20-22 $\mu$ A. After about 14 hours of irradiation, the pressure in the XeHPC dropped to 185 bar and did not change till the end of the irradiation cycle. Upon completion of exposure, part of the gas from XeHPC was bypassed into a separate reservoir to measure the xenon composition by mass-analyzer QMA-200. After the opening of the XeHPC, an inner assembly without xenon was fixed at the Ge-detector for measurement of $\gamma$-spectra of radionuclides produced in the XeHPC and the background during 15 hours. A visual inspection of the inner assembly indicated that the surfaces of its elements were covered with a siskin green layer. Using SEM (scanning electron microscopy) studies and MPRA (microprobe roentgen analysis) [1], the element compositions of the synthesized micro-objects and micro-particles were determined. In order to explain the observed anomalies in the formation of new elements in the micro-particles and micro-objects, nuclear fission and synthesis reactions should be used.
\end{abstract}

Key words: Element composition, structure, irradiation, xenon, $\gamma$-rays, maximum energy.

\section{Introduction}

The structure and element composition of the synthesized particles and objects as well as the surface structure of the inner components of deuterium high-pressure chambers (DHPC and FDHPC) have been previously studied using a series of metals and alloys placed in a gas of molecular deuterium under high pressure and influenced by braking $\gamma$-rays with $\mathrm{E}_{\max }$ of $10 \mathrm{MeV}[1,2]$ and $23 \mathrm{MeV}$ [3]. Analogous investigations with the purpose of studying possible nuclear reactions have been also carried out using high-pressure chambers filled with deuterium (DHPC) [4], hydrogen (HHPC) [5, 6] and spectrally pure helium [7-9] without any metallic samples inside

Corresponding author: R. Wisniewski, professor, research fields: high pressure physics and technology, $\gamma$-irradiation nuclear reaction in dense gases environments. under braking radiation with $\mathrm{E}_{\max }$ of $10 \mathrm{MeV}$. The results on the nuclear reactions proceeding in dense gases $\mathrm{H}_{2}, \mathrm{D}_{2}$ and $\mathrm{He}$ are reviewed in Ref. [10]. Phenomenological reactions leading to the observed anomalies from [1-10] are presented in Ref. [11].

The goal of this research is to study nuclear reactions taking place with the formation of synthesized structures from new elements in natural xenon at gas pressure in the XeHPC of $\sim 270$ bar under a long-term exposure to braking $\gamma$-rays with $\mathrm{E}_{\max }$ of 10 $\mathrm{MeV}$ (see a more detailed description in Refs. [11-14]).

\section{Materials and Methods}

2.1 The Technique of Irradiation with Braking $\gamma$-rays and XeHPC Parameters

The XeHPC (xenon high- pressure chamber) shown 
in Fig. 1 is a barrel (2) of $21.3 \mathrm{~mm}$ inner diameter and $112 \mathrm{~mm}$ length, fabricated from 12X18H10T stainless steel. The inner diameter of this cylinder is $13 \mathrm{~mm}$. Its front wall facing towards $\gamma$-ray flux (1) has a thickness of $4 \mathrm{~mm}$. The XeHPC chamber body is cooled by water flowing through a copper pipe $5 \mathrm{~mm}$ in diameter (3). There are two liners inside the steel barrel. The outer case (4) of inner diameter $11 \mathrm{~mm}$ is made of duralumin D16T. The inside liner from pure reactor aluminum is composed of two parts: front and rear cylinders $(6 a, b)$ of $29 \mathrm{~mm}$ length each and with an inner diameter of $10 \mathrm{~mm}$. The front and rear sleeves $(5 \mathrm{a}, \mathrm{b})$ of the inside liner are made of reactor aluminum as well. The thickness of the front sleeve is $2 \mathrm{~mm}$.

Table 1 shows the element concentrations in aluminum which is the material of the inserted front and rear thin-walled cylinders $(6 a, b)$ and sleeves $(5 a$, b) obtained by MPRA.

The XeHPC was filled with xenon up to a pressure of 270 bar. The initial xenon composition from the vessel was analyzed using gas mass-analyzer QMS-200. Within the limits of error, the isotopic ratio corresponds to the natural one.

The XeHPC chamber was exposed during 43 hours $\left(1.548 \times 10^{5} \mathrm{~s}\right)$ to braking radiation with $\mathrm{E}_{\max }$ of 10 $\mathrm{MeV}$ at the electron accelerator MT-25. The average current at the target was $20-22 \mu \mathrm{A}$, and the integral flux was equal to $2.4 \times 10^{19}$ electrons. The irradiation lasted 7-8 hours per day. The XeHPC pressure was measured at room temperature prior to irradiating and upon completion. At the end of the first hours, the chamber pressure rose from 270 bar to 320 bar upon reaching steady state. After about 14 hours of irradiating, the pressure in the cooled XeHPC dropped to 185 bar. Such pressure increased up to 230 bar under the steady state regime which was preserved till the end of the irradiation cycle.

After the irradiation the chamber was opened, and the cylinders from the XeHPC (Fig. 1, p. 4, 5, 6) were placed, without dismantling, in a Ge-detector (Canberra)

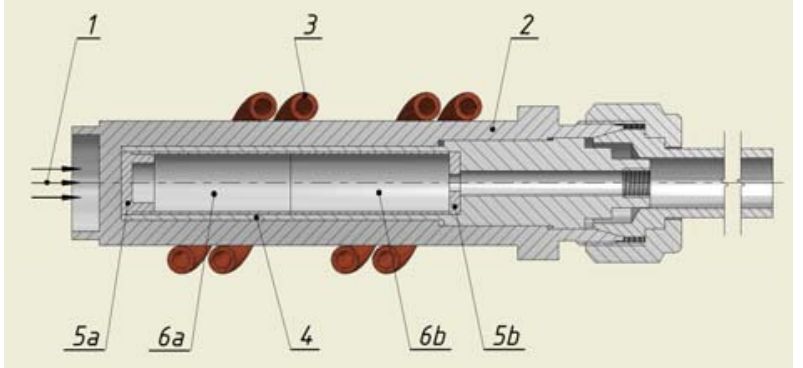

Fig. 1 XeHPC high pressure chamber (for details see text).

Table 1 The element composition of the original aluminum.

\begin{tabular}{llllll}
\hline Element & $\mathrm{C}$ & $\mathrm{O}$ & $\mathrm{Mg}$ & $\mathrm{Al}$ & $\mathrm{Si}$ \\
\hline Over area & 16.12 & 2.13 & 0.52 & 80.59 & 0.65 \\
At point & 22.18 & 2.10 & 0.11 & 75.25 & 0.36 \\
\hline
\end{tabular}

with a resolution of $1.5 \mathrm{keV}$ at the line of $1,332.5 \mathrm{keV}$ $\left({ }^{60} \mathrm{Co}\right.$ line $)$ for measurement of $\gamma$-spectra. The background and $\gamma$-spectra were measured during 15 hours.

Upon completion of measurements, the entire assembly was dismantled. The outside surface of the outer barrel from D16T (Fig. 1, p. 2), as well as the inner surfaces of the liners and aluminum sleeves (Fig. 1$, p. 5,6$)$ were found to be covered with a siskin green layer, to a greater extent at the front than at the cylinder's end.

Apart from this, about 20-30 dark particles of millimeter size which had spilled from the inner chamber could be observed visually.

\subsection{SEM and MPRA Studies of the Chemical Compositions of Synthesized Particles}

Figs. 2a-2d show images of several particles of complex shape with light inclusions (dots) in the surface. In Figs. 2e-2h, some of the MPRA spectra measured at indicated points and area are given. The element compositions in atomic percent are displayed for 8 points in Table 2 and for 7 areas in Table 3. All in all, analysis was done for 20 points and over 10 areas. The error in the measured values from the tables is given in the second decimal place.

The number of spectrum assigned during the analysis is in the upper row of the table. One can see 

Dense Xenon Gas (270 bar) by Y-Rays with a Maximum Energy of $10 \mathrm{MeV}$

from Tables 2 and 3 that carbon was not taken into account although its lines are present in the spectrum. For the purposes of visibility, convenience and
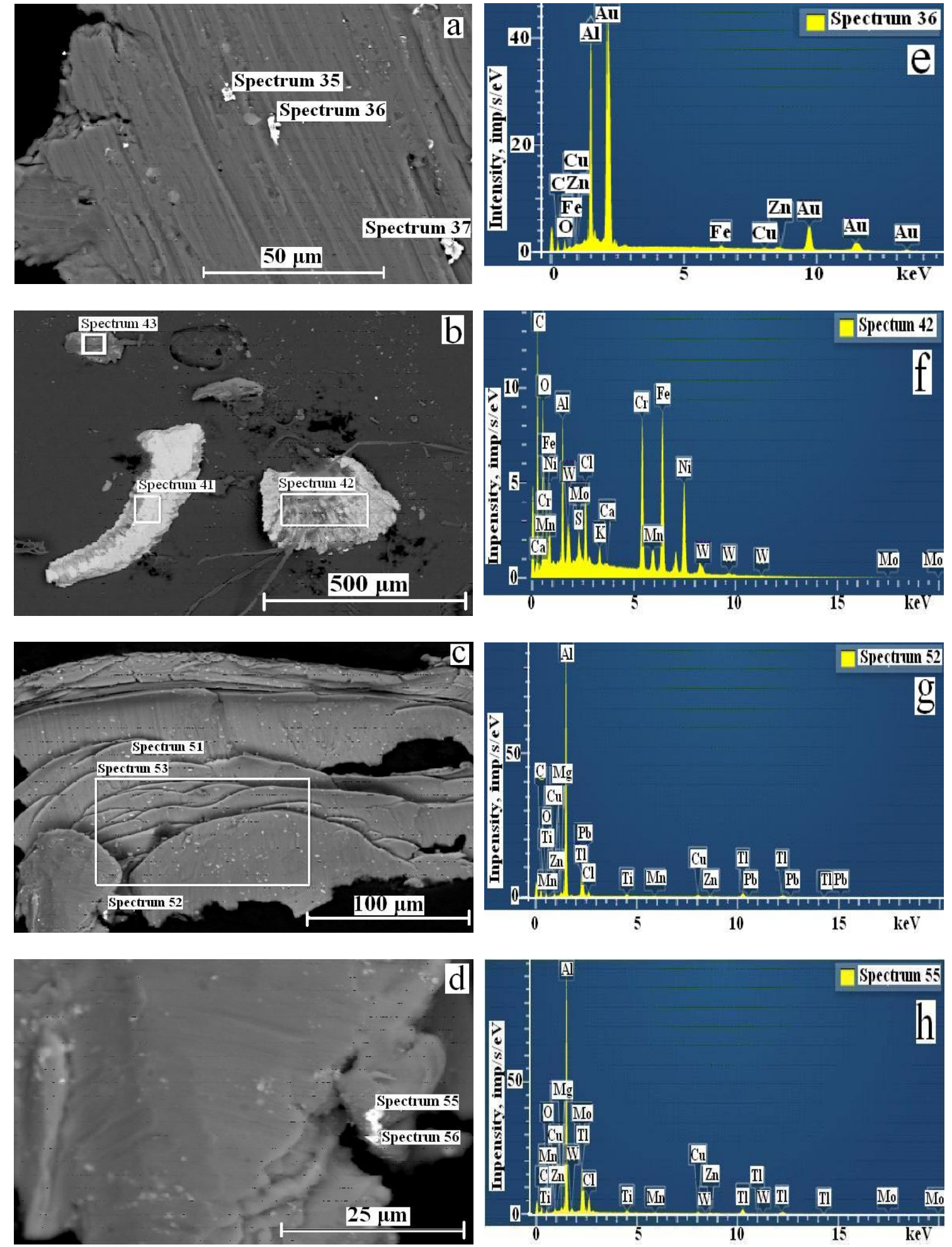

Fig. 2 Examples of the points and areas on the particles being investigated and characteristic X-rays spectra. compactness of presenting data, the figures display histograms with averaged element compositions in indicated amounts, which were measured at points and

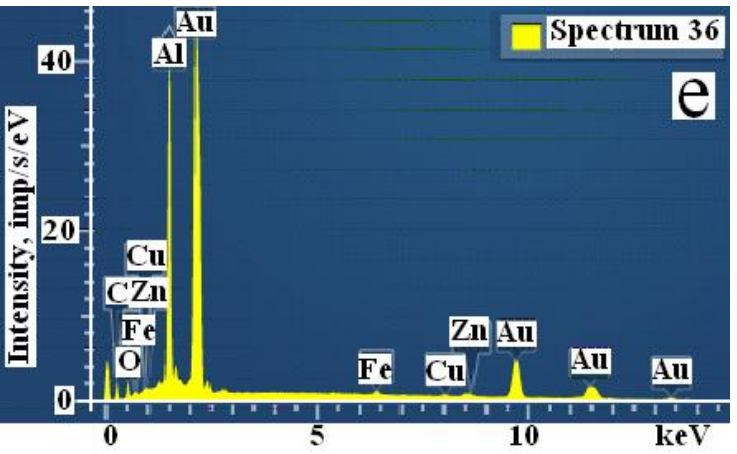

. 
A Study of Changes in the Element Composition and Structure of Surfaces under Irradiation of Dense Xenon Gas (270 bar) by Y-Rays with a Maximum Energy of $10 \mathrm{MeV}$

Table 2 The element compositions for 8 points on the particles (partially shown in Fig. 2).

\begin{tabular}{|c|c|c|c|c|c|c|c|c|}
\hline & 33 & 35 & 36 & 39 & 40 & 52 & 55 & 65 \\
\hline $\mathrm{O}$ & 4.85 & 4.42 & 16.97 & 83.16 & 78.11 & 11.06 & 8.71 & 86.4 \\
\hline $\mathrm{Na}$ & - & - & - & - & - & - & - & 3.38 \\
\hline $\mathrm{Mg}$ & 0.20 & - & - & 1.35 & 1.65 & 0.95 & 1.05 & 0.17 \\
\hline $\mathrm{Al}$ & 59.81 & 78.85 & 52.46 & 3.02 & 1.63 & 77.8 & 72.3 & 2.45 \\
\hline $\mathrm{Si}$ & 0.36 & - & - & 6.55 & 6.24 & - & - & 5.60 \\
\hline $\mathrm{P}$ & - & - & - & - & 0.22 & - & - & - \\
\hline $\mathrm{S}$ & - & - & - & 0.27 & 0.59 & - & - & 0.19 \\
\hline $\mathrm{Cl}$ & - & - & - & 0.50 & 1.07 & 1.86 & 6.38 & 0.60 \\
\hline K & - & - & - & 0.62 & 0.27 & - & - & 0.13 \\
\hline $\mathrm{Ca}$ & - & - & - & 3.43 & 4.52 & - & - & 0.92 \\
\hline $\mathrm{Ti}$ & - & - & - & - & - & 0.82 & 0.89 & - \\
\hline $\mathrm{Cr}$ & 4.73 & - & - & - & - & - & - & - \\
\hline $\mathrm{Mn}$ & - & - & - & - & - & 0.38 & 0.26 & - \\
\hline $\mathrm{Fe}$ & 30.03 & - & 1.01 & 1.10 & 5.28 & - & - & 0.16 \\
\hline $\mathrm{Cu}$ & - & 0.25 & 0.69 & - & - & 1.80 & 1.44 & - \\
\hline $\mathrm{Zn}$ & 0.02 & - & 0.18 & - & 0.42 & 0.85 & 0.83 & - \\
\hline Mo & - & - & - & - & - & - & 1.72 & - \\
\hline W & - & - & - & - & - & - & 0.01 & - \\
\hline $\mathrm{Au}$ & - & 16.48 & 28.69 & - & - & - & - & - \\
\hline $\mathrm{Tl}$ & - & - & - & - & - & 4.05 & 6.41 & - \\
\hline $\mathrm{Pb}$ & - & - & - & - & - & 0.43 & - & - \\
\hline
\end{tabular}

Table 3 The element compositions for 7 areas on the particles (partially shown in Fig. 2).

\begin{tabular}{|c|c|c|c|c|c|c|c|}
\hline & 38 & 41 & 42 & 43 & 45 & 53 & 66 \\
\hline $\mathrm{O}$ & 77.38 & 9.20 & 35.33 & 78.06 & 46.37 & - & - \\
\hline $\mathrm{Na}$ & 0.73 & - & - & 5.29 & - & - & - \\
\hline $\mathrm{Mg}$ & 2.48 & - & - & 1.97 & - & 13.6 & - \\
\hline $\mathrm{Al}$ & 2.27 & 1.32 & 11.13 & 1.70 & 1.13 & 83.3 & - \\
\hline $\mathrm{Si}$ & 7.18 & 1.11 & 0.47 & 2.38 & 0.17 & - & 14.6 \\
\hline $\mathrm{P}$ & 0.14 & - & - & - & - & - & - \\
\hline S & 0.39 & - & - & 3.65 & - & - & 20.3 \\
\hline $\mathrm{Cl}$ & 2.60 & 0.51 & 4.56 & 1.66 & 3.32 & 0.10 & 65.1 \\
\hline K & 0.49 & - & 1.00 & 1.27 & 0.64 & - & - \\
\hline $\mathrm{Ca}$ & 4.91 & - & 0.18 & 0.64 & - & 0.10 & - \\
\hline $\mathrm{Cr}$ & - & 17.05 & 12.45 & - & 13.01 & - & - \\
\hline $\mathrm{Mn}$ & - & 1.50 & 0.36 & - & 0.31 & 0.38 & - \\
\hline $\mathrm{Fe}$ & 1.39 & 60.17 & 17.87 & - & 14.15 & 0.19 & - \\
\hline $\mathrm{Ni}$ & - & 8.01 & 14.76 & - & 18.0 & - & - \\
\hline $\mathrm{Cu}$ & - & - & - & - & - & 2.15 & - \\
\hline $\mathrm{Zn}$ & 0.04 & - & - & 1.87 & - & 0.18 & - \\
\hline $\mathrm{Nb}$ & - & - & - & - & 0.31 & - & - \\
\hline Mo & - & 1.13 & 0.83 & - & 1.42 & - & - \\
\hline $\mathrm{Ba}$ & - & - & - & 1.51 & - & - & - \\
\hline W & - & - & 1.06 & - & 1.17 & - & - \\
\hline
\end{tabular}

areas (Figs. 3 and 4). As may be seen from the tables and figures, new chemical elements which were absent in the XeHPC volume prior to irradiation are synthesized in the reactions of $\gamma$-quanta and xenon under high pressure. Conspicuous is that the synthesized elements are distributed over certain 

Dense Xenon Gas (270 bar) by y-Rays with a Maximum Energy of $10 \mathrm{MeV}$

groups. The group of elements up to zinc has the largest reaction yield. Another group of elements falls in the range $Z=40-50$. The group of heavy elements from tungsten to lead has a high reaction yield as well.

\subsection{SEM and MPRA studies of sleeves}

The SEM image in Fig. 5a displays the bottom of the FS (front sleeve) from Fig. 1(5a) with a cavity of 2 $\mathrm{mm}$ in depth and $7 \mathrm{~mm}$ in diameter as well as structures thickly covering both the bottom and walls. In Fig. $5 b$, the same structure is shown with a greater magnification. The x-ray output from the cavity walls is very small, which did not allow us to make MPRA. Fig. 5c displays a SEM image of the end part of the FS and the MPRA spectrum at point 76 from Fig. 5d.

The RS (rear sleeve) (see Fig.1, 5b) was cut along its axis of symmetry into two halves which were studied by SEM and MPRA. Figs. $6 a$ and $6 \mathrm{~b}$ show a SEM image of points on the surface of one of the FS halves, with respective MPRA spectra given in Figs. $6 \mathrm{c}$ and $6 \mathrm{~d}$.
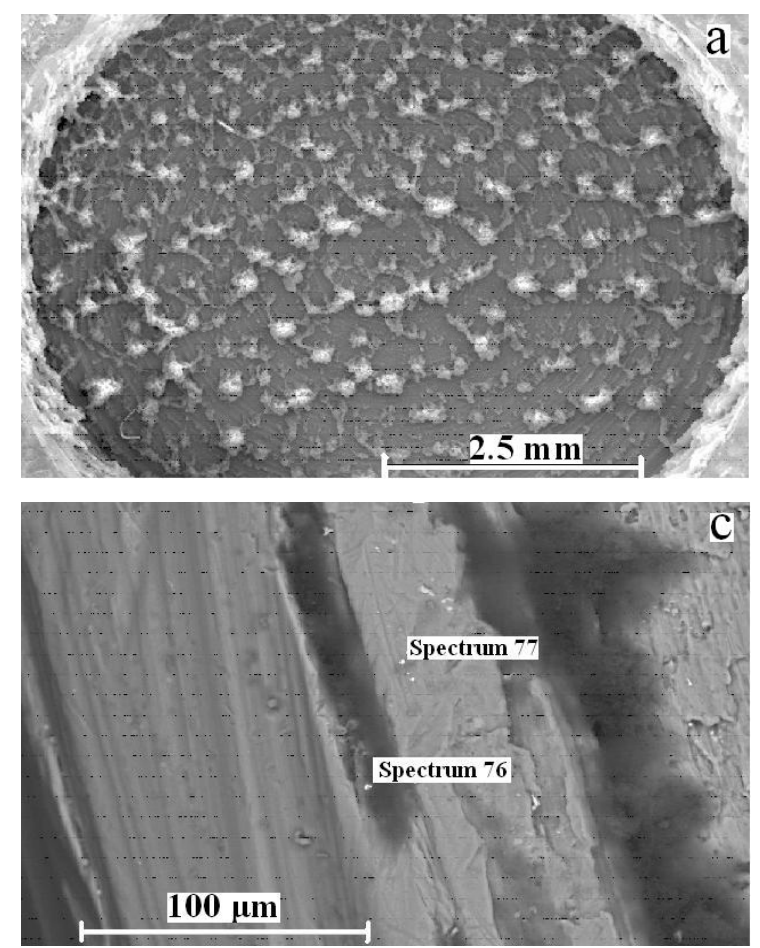

Particles

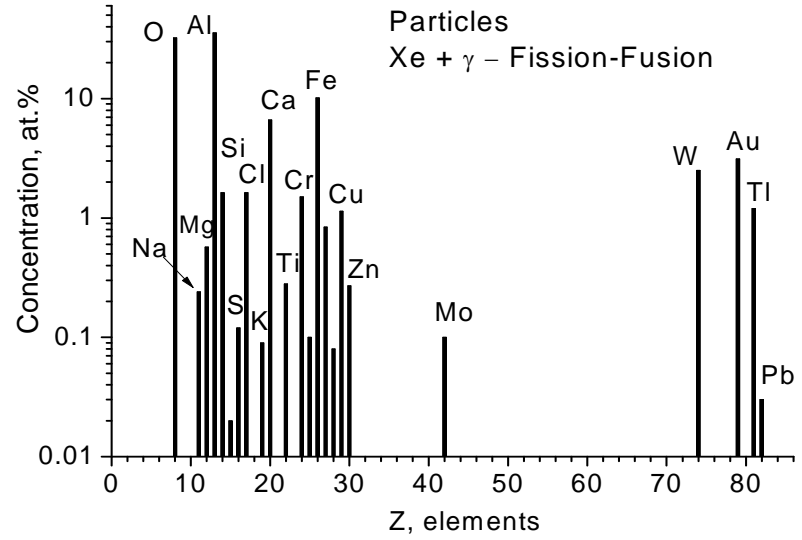

Fig. 3 The averaged element composition for 16 points.

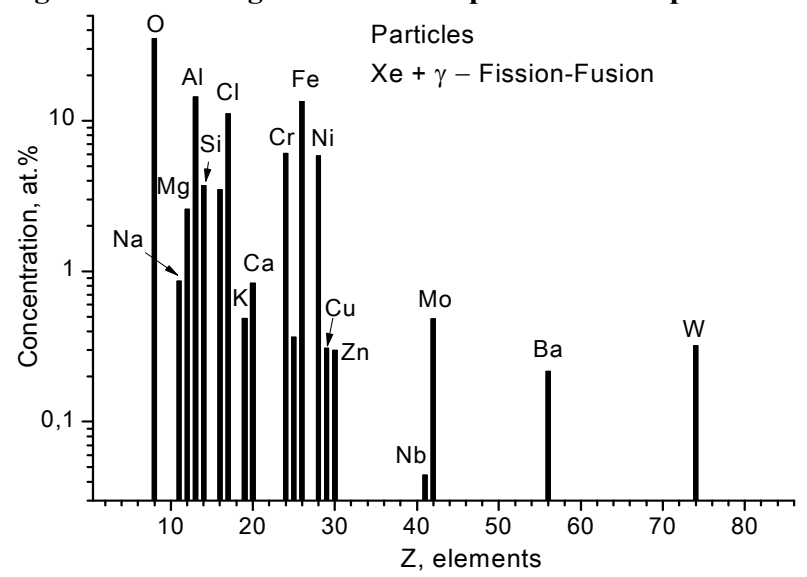

Fig. 4 The averaged element composition for 7 areas.
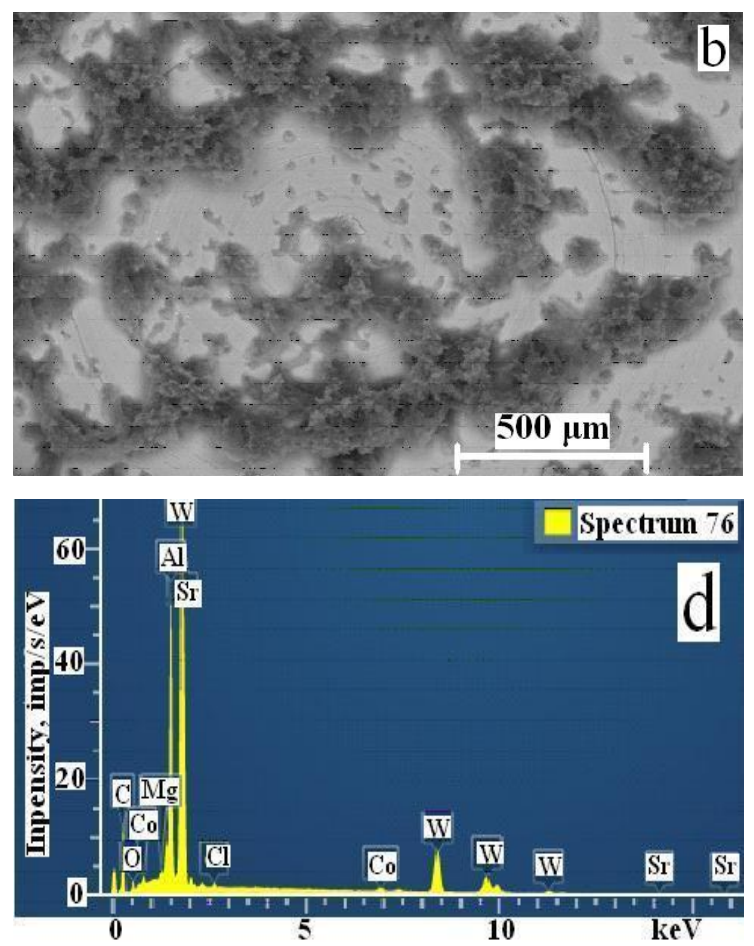

Fig. 5 SEM image of the input front sleeve and characteristic X-rays spectrum in chosen point. 

Dense Xenon Gas (270 bar) by y-Rays with a Maximum Energy of $10 \mathrm{MeV}$
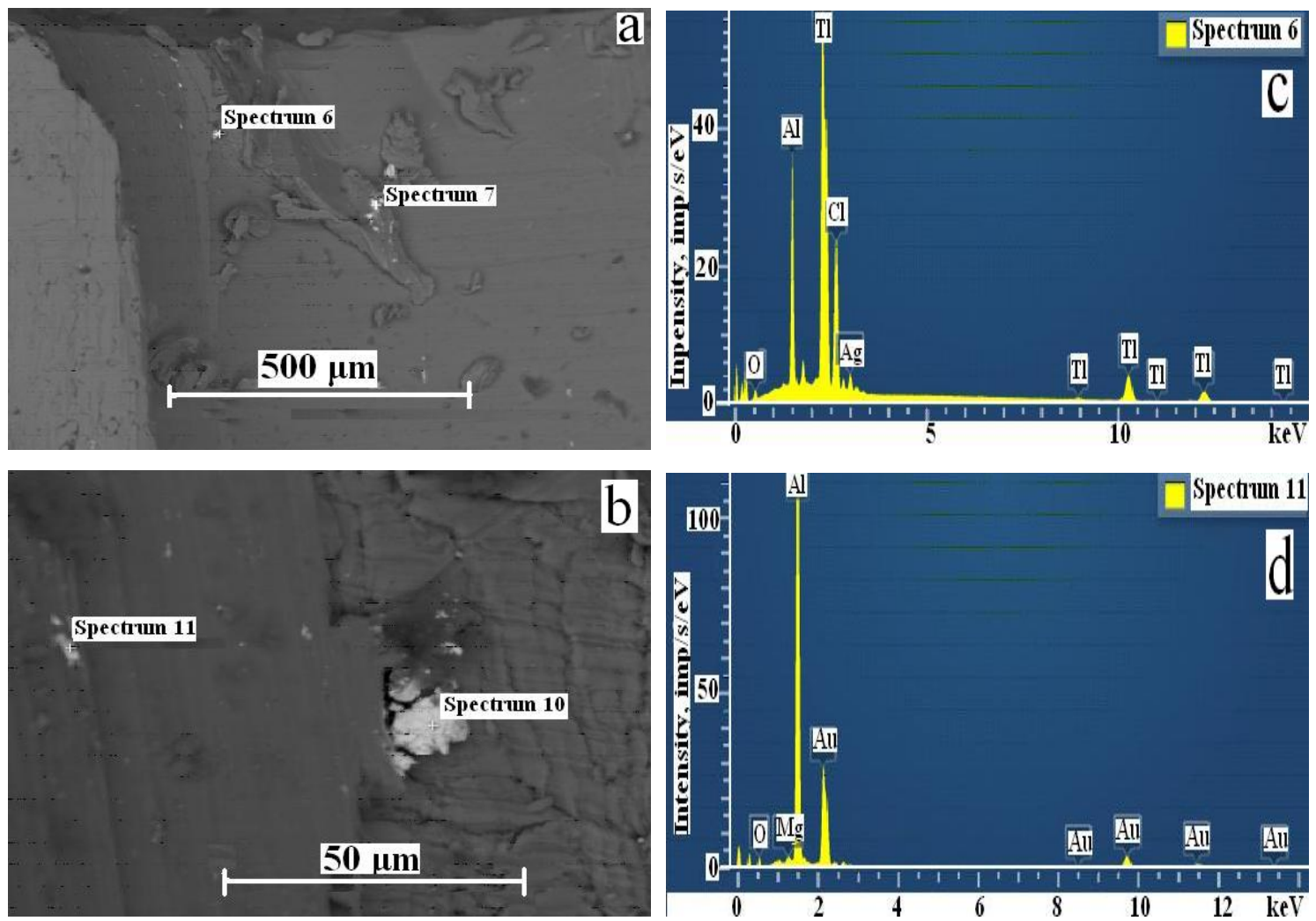

Fig. 6 SEM images of the output rear sleeve and characteristic X-rays spectra in chosen points.

The element compositions measured at 7 points of the front sleeve and 9 points of the rear sleeve can be found in Tables 4 and 5. The histograms in Figs. 7 and 8 contain averaged element compositions for the points at the FS and RS.

The new elements formed on the sleeves are distributed over the same groups as the synthesized ones on the particles: elements up to zinc, elements with $Z=40-50$, as well as heavy elements. The latter group has the highest reaction yield. Within the first approximation, no significant difference between the element yields at the front and rear sleeves is observed.

\subsection{SEM and MPRA Studies of Liners}

Figs. 9a and 9b, and Figs. 10a and 10b present patches of surfaces at the front (FAL) and rear (RAL) aluminium liners (Fig. 1, 6a, b) with light microparticles where MPRA was done at the marked points, shown in Figs. 9d and 9e, and Figs. 10c and 10 d. A SEM image of surface at the front liner strewn with small beads that form the siskin green coating is given in Figs. 9c and 9f at different scales. Attempts to make analysis for this coating did not meet with success; therefore, it was decided to take into account carbon for the liners.

In Tables 6-9, you can find the element compositions measured at points and areas for FAL and RAL. The corresponding averaged element compositions may be found in histograms in Figs. 11-14. Noteworthy is that heavy elements are practically absent and elements with $Z=40-50$ are weakly present in the liners.

Remarks. Long-term irradiation (43 hours) of the vacuumized $\left(10^{-2}\right.$ torr. $)$ chamber of the same assembly, shown in Fig. 1, did not lead to the formation of new chemical elements.

The experiments aimed at observing foreign elements had a qualitative rather than quantitative character since: a) The choice of objects to be analyzed was purely subjective. As a rule, we measured the most appealing and bright objects with a 

Dense Xenon Gas (270 bar) by y-Rays with a Maximum Energy of $10 \mathrm{MeV}$

Table 4 The element compositions for 7 points of the FS (two of them shown in Fig. 5).

\begin{tabular}{|c|c|c|c|c|c|c|c|}
\hline & 70 & 71 & 72 & 76 & 77 & 79 & 80 \\
\hline $\mathrm{O}$ & 8.05 & 23.21 & 25.5 & 14.82 & - & 14.94 & 6.33 \\
\hline $\mathrm{Mg}$ & - & - & - & 1.87 & 0.51 & - & - \\
\hline $\mathrm{Al}$ & 49.81 & 67.05 & 41.0 & 46.3 & 89.17 & 51.71 & 66.83 \\
\hline $\mathrm{Si}$ & 0.5 & - & - & - & 0.8 & - & 0.94 \\
\hline S & - & - & - & - & 0.22 & - & 16.51 \\
\hline $\mathrm{Cl}$ & 0.41 & 3.82 & 0.88 & 1.06 & 3.27 & 1.88 & - \\
\hline $\mathrm{Fe}$ & - & - & 0.54 & - & 0,15 & 0.86 & - \\
\hline $\mathrm{Co}$ & - & - & 9.26 & 1.39 & - & 1.7 & - \\
\hline $\mathrm{Ni}$ & 41.23 & - & - & - & - & - & - \\
\hline $\mathrm{Cu}$ & - & - & - & - & - & 0.68 & - \\
\hline $\mathrm{Ge}$ & - & - & - & - & - & - & 9.39 \\
\hline $\mathrm{Sr}$ & - & - & - & 3.96 & - & - & - \\
\hline $\mathrm{Cd}$ & - & 5.92 & - & - & 5.88 & - & - \\
\hline W & - & - & 22.82 & 30.6 & - & 28.23 & - \\
\hline
\end{tabular}

Table 5 The element compositions for 9 points of the RS (some of them shown in Fig. 6).

\begin{tabular}{llllllllll}
\hline & 6 & 7 & 10 & 11 & 22 & 24 & 29 & 30 & 32 \\
\hline $\mathrm{O}$ & 9.33 & 41.9 & 8.44 & 11.6 & 30.9 & 10.0 & 19.2 & - & 15.2 \\
$\mathrm{Mg}$ & - & - & - & 1.0 & 1.61 & 16.8 & - & - & - \\
$\mathrm{Al}$ & 32.0 & 38.6 & 15.8 & 75.9 & 26.7 & - & 13.1 & 61.0 & 21.5 \\
$\mathrm{Si}$ & - & - & - & - & 0.19 & - & 1.04 & 4.74 & - \\
$\mathrm{S}$ & - & - & - & - & - & - & 2.06 & 5.26 & - \\
$\mathrm{Cl}$ & 30.7 & 6.6 & 40.8 & - & 0.79 & 0.30 & 64.6 & 29.0 & - \\
$\mathrm{K}$ & - & - & - & - & 1.03 & 0.40 & - & - & - \\
$\mathrm{Cr}$ & - & - & - & - & - & - & - & - & 11.2 \\
$\mathrm{Mn}$ & - & - & - & - & - & - & - & - & 0.85 \\
$\mathrm{Fe}$ & - & - & - & - & - & - & - & - & 35.1 \\
$\mathrm{Ni}$ & - & - & - & - & 0.18 & - & - & - & 4.85 \\
$\mathrm{Cu}$ & - & - & - & - & 27.1 & 49.5 & - & - & - \\
$\mathrm{Zn}$ & - & - & - & - & 11.5 & 23.0 & - & - & - \\
$\mathrm{Ag}$ & 3.27 & - & 8.66 & - & - & - & - & - & - \\
$\mathrm{Ta}$ & - & - & - & - & - & - & - & - & 11.3 \\
$\mathrm{Au}$ & - & - & - & 11.5 & - & - & - & - & - \\
$\mathrm{Tl}$ & 24.7 & 12.9 & 26.3 & - & - & - & - & - & - \\
\hline
\end{tabular}

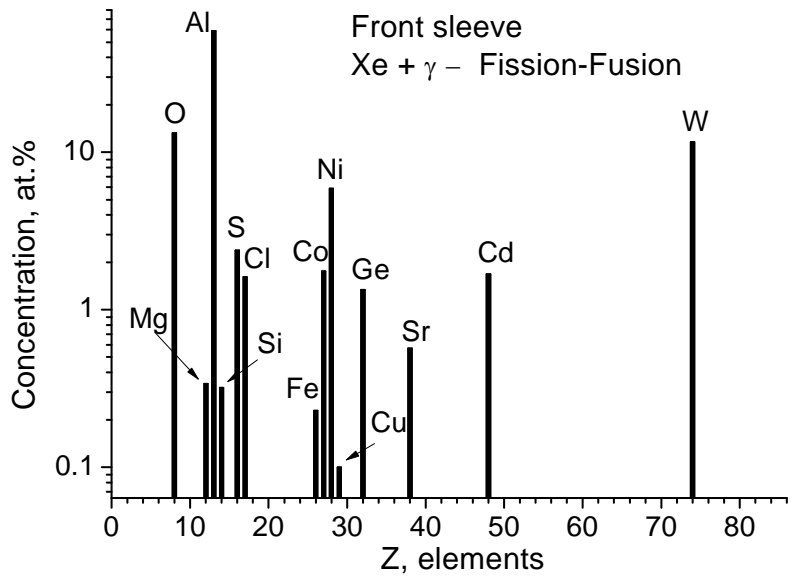

Fig. 7 The averaged element composition for 7 points (FS).

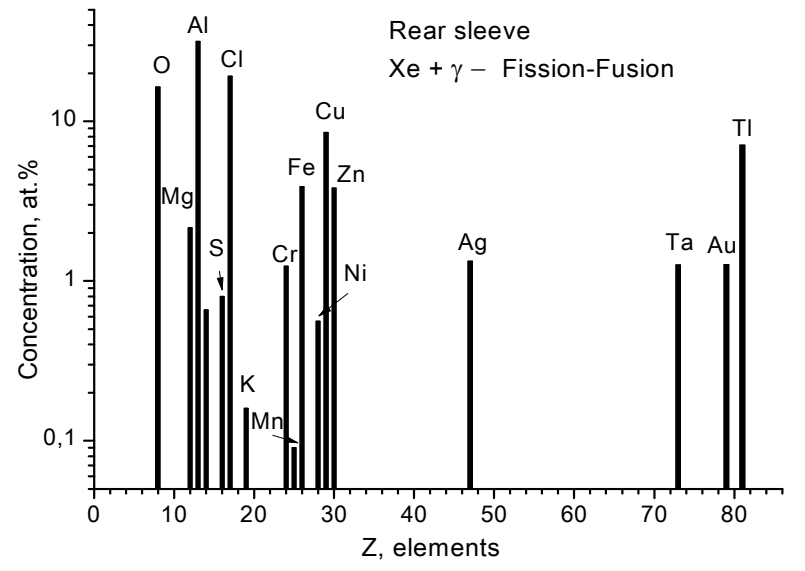

Fig. 8 The averaged element composition for 9 points (RS). 
A Study of Changes in the Element Composition and Structure of Surfaces under Irradiation of Dense Xenon Gas (270 bar) by Y-Rays with a Maximum Energy of $10 \mathrm{MeV}$
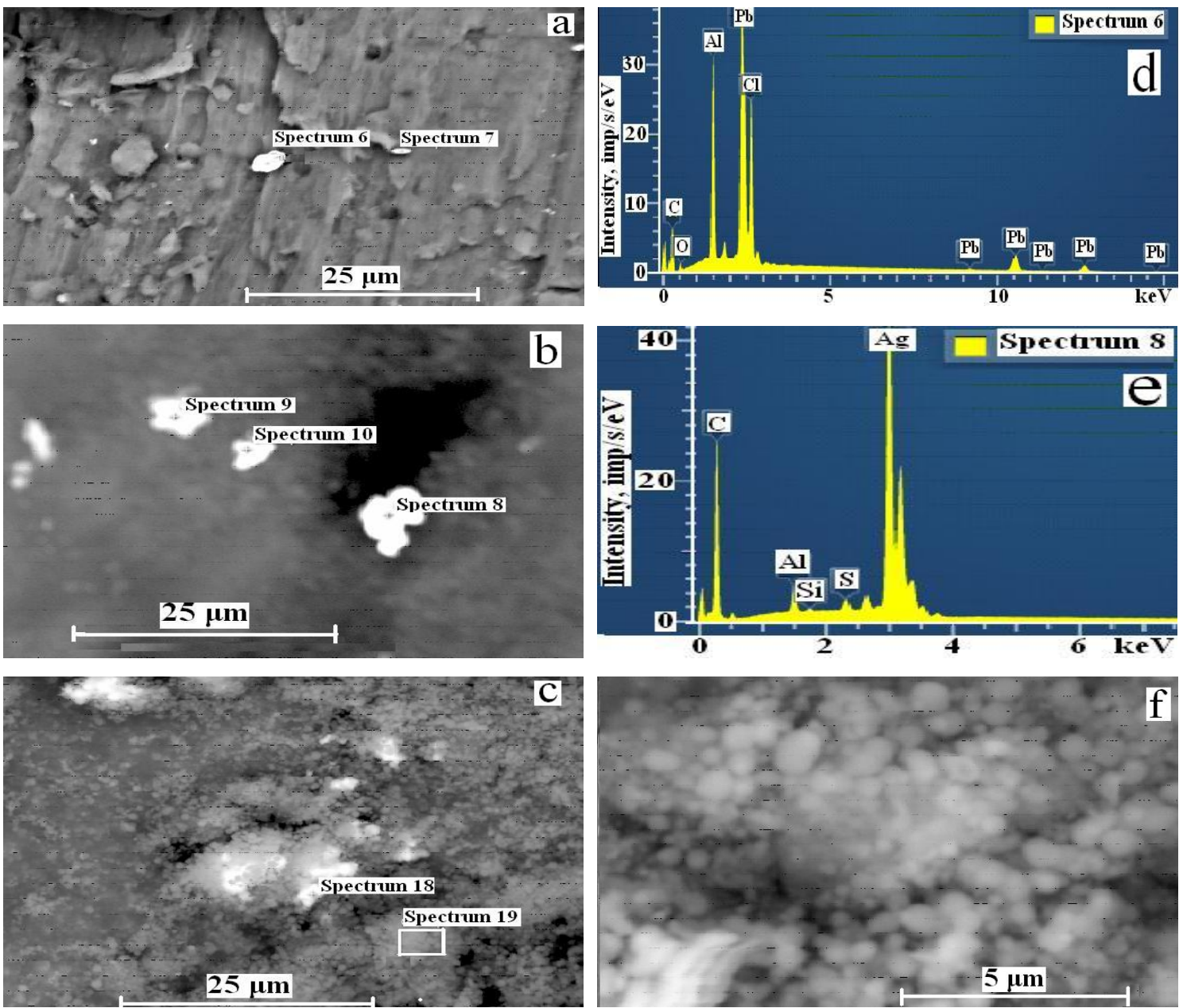

Fig. 9 SEM images of the front aluminum liner and characteristic of X-rays spectrum for two points.
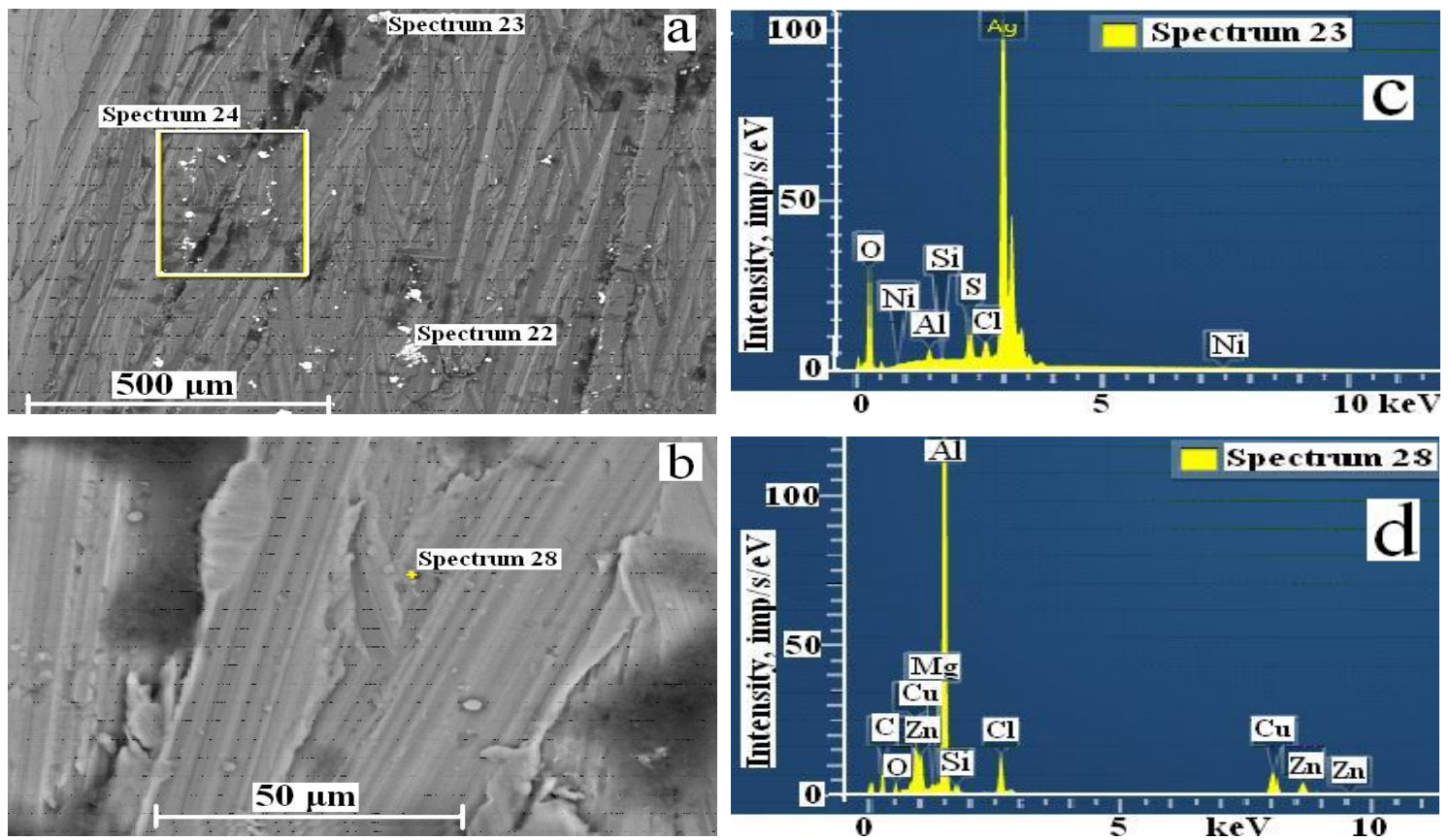

Fig. 10 Two SEM images of the rear aluminum liner and characteristic X-rays spectrum obtained at points 23 and 28. 

Dense Xenon Gas (270 bar) by y-Rays with a Maximum Energy of $10 \mathrm{MeV}$

Table 6 The element compositions at 7 points of FAL (see Fig. 9).

\begin{tabular}{|c|c|c|c|c|c|c|c|}
\hline & 3 & 6 & 7 & 9 & 12 & 15 & 19 \\
\hline $\mathrm{C}$ & 42.0 & 65.17 & 57.85 & 81.36 & 69.84 & 66.49 & 90.27 \\
\hline $\mathrm{O}$ & 3.08 & 3.77 & 3.61 & 14.20 & - & 28.4 & - \\
\hline $\mathrm{Mg}$ & - & - & 0.20 & - & - & 0.55 & - \\
\hline $\mathrm{Al}$ & 1.82 & 11.25 & 34.5 & 0.85 & 16.32 & 1.51 & 5.98 \\
\hline $\mathrm{Si}$ & 0.73 & - & 0.14 & 0.09 & 0.14 & 1.84 & 0.15 \\
\hline $\mathrm{P}$ & - & - & - & - & - & 0.07 & - \\
\hline S & - & - & - & 0.24 & - & 0.03 & 0.10 \\
\hline $\mathrm{Cl}$ & 0.23 & 11.87 & 2.06 & 0.18 & 0.28 & 0.16 & 0.24 \\
\hline $\mathrm{Ca}$ & - & - & - & 0.22 & - & 0.24 & - \\
\hline V & 0.15 & & - & - & - & 0.09 & - \\
\hline $\mathrm{Cr}$ & 10.55 & - & - & - & - & - & 0.02 \\
\hline $\mathrm{Mn}$ & 6.4 & - & - & - & - & - & 0.02 \\
\hline $\mathrm{Fe}$ & 32.89 & - & - & 2.79 & - & 0.62 & 2.97 \\
\hline $\mathrm{Ni}$ & 2.15 & - & - & - & - & - & - \\
\hline $\mathrm{Cu}$ & - & - & 0.04 & 0.02 & - & - & 0.14 \\
\hline $\mathrm{Zn}$ & - & - & - & 0.05 & - & - & 0.06 \\
\hline $\mathrm{Ag}$ & - & - & - & - & 13.42 & - & - \\
\hline $\mathrm{Cd}$ & - & - & 1.60 & - & - & - & - \\
\hline $\mathrm{Sb}$ & - & - & - & - & - & - & 0.04 \\
\hline $\mathrm{Ba}$ & - & - & - & - & - & - & 0.01 \\
\hline $\mathrm{Pb}$ & - & 7.94 & - & - & - & - & - \\
\hline
\end{tabular}

Table 7 The element compositions for 9 points at RAL (see Fig. 10).

\begin{tabular}{|c|c|c|c|c|c|c|c|c|c|}
\hline & 13 & 14 & 15 & 16 & 22 & 23 & 28 & 29 & 30 \\
\hline $\mathrm{C}$ & 99.14 & 87.89 & 59.57 & 72.65 & 31.4 & 68.2 & 56.1 & 63.82 & 62.6 \\
\hline $\mathrm{O}$ & & 9.80 & 2.64 & & & & 3.92 & 14.74 & 10.2 \\
\hline $\mathrm{Mg}$ & & & 0.55 & 0.29 & & & & 5.82 & 5.35 \\
\hline $\mathrm{Al}$ & 0.02 & & 34.34 & 23.15 & 7.55 & 1.37 & 32.4 & 8.46 & 15.9 \\
\hline $\mathrm{Si}$ & 0.11 & 0.05 & & & 0.16 & 0.12 & 0.47 & 2.01 & 0.50 \\
\hline $\mathrm{S}$ & 0.18 & 0.05 & & & 3.57 & 2.79 & & & \\
\hline $\mathrm{Cl}$ & 0.50 & 2.20 & 0.05 & & 0.82 & 0.51 & 1.81 & 5.15 & 5.33 \\
\hline K & & & 0.02 & & & & & & 0.08 \\
\hline $\mathrm{Mn}$ & & & 0.19 & 0.04 & & & & & \\
\hline $\mathrm{Fe}$ & 0.05 & 0.01 & 0.62 & 0.03 & & & & & 0.02 \\
\hline $\mathrm{Ni}$ & & & & & & 0.11 & & & \\
\hline $\mathrm{Cu}$ & & & 2.02 & 3.84 & & & 3.91 & & 0.02 \\
\hline $\mathrm{Zn}$ & & & & & & & 1.39 & & \\
\hline $\mathrm{Ag}$ & & & & & 56.5 & 26.9 & & & \\
\hline
\end{tabular}

Table 8 The element compositions for 5 areas at FAL (see Fig. 9).

\begin{tabular}{llllll}
\hline & 16 & 17 & 18 & 19 & 20 \\
\hline $\mathrm{C}$ & 80.26 & 91.01 & 91.55 & 93.56 & 74.19 \\
$\mathrm{O}$ & - & - & - & 6.03 & - \\
$\mathrm{Mg}$ & 0.10 & 0.07 & 0.04 & - & 0.13 \\
$\mathrm{Al}$ & 18.8 & 8.07 & 7.60 & 0.01 & 25.36 \\
$\mathrm{Si}$ & 0.14 & 0.14 & 0.10 & 0.08 & 0.18 \\
$\mathrm{~S}$ & 0.03 & 0.08 & 0.08 & 0.09 & 0.02 \\
$\mathrm{Cl}$ & 0.63 & 0.63 & 0.63 & 0.23 & 0.12 \\
$\mathrm{Ni}$ & 0.04 & - & - & - & - \\
\hline
\end{tabular}


Dense Xenon Gas (270 bar) by y-Rays with a Maximum Energy of $10 \mathrm{MeV}$

Table 9 The element compositions for 6 areas at RAL (see Fig. 10).

\begin{tabular}{|c|c|c|c|c|c|c|}
\hline & 24 & 25 & 26 & 27 & 31 & $17-2$ \\
\hline $\bar{C}$ & 64.8 & 94.74 & 84.74 & 60.23 & 45.75 & 95.07 \\
\hline $\mathrm{O}$ & - & - & - & 1.95 & 10.65 & 4.53 \\
\hline $\mathrm{F}$ & - & - & - & - & 1.07 & - \\
\hline $\mathrm{Mg}$ & 0.23 & - & 0.13 & 0.20 & 0.85 & - \\
\hline $\mathrm{Al}$ & 34.25 & 4.91 & 14.78 & 37.27 & 32.96 & 0.11 \\
\hline $\mathrm{Si}$ & 0.29 & 0.09 & 0.16 & 0.24 & 7.59 & 0.08 \\
\hline $\mathrm{S}$ & 0.04 & 0.08 & 0.03 & 0.02 & - & 0.08 \\
\hline $\mathrm{Cl}$ & 0.20 & 0.18 & 0.16 & 0.09 & 1.13 & 0.08 \\
\hline $\mathrm{Fe}$ & 0.02 & - & - & - & - & 0.02 \\
\hline $\mathrm{Cu}$ & - & - & - & - & - & 0.03 \\
\hline $\mathrm{Ag}$ & 0.17 & - & - & - & - & - \\
\hline
\end{tabular}

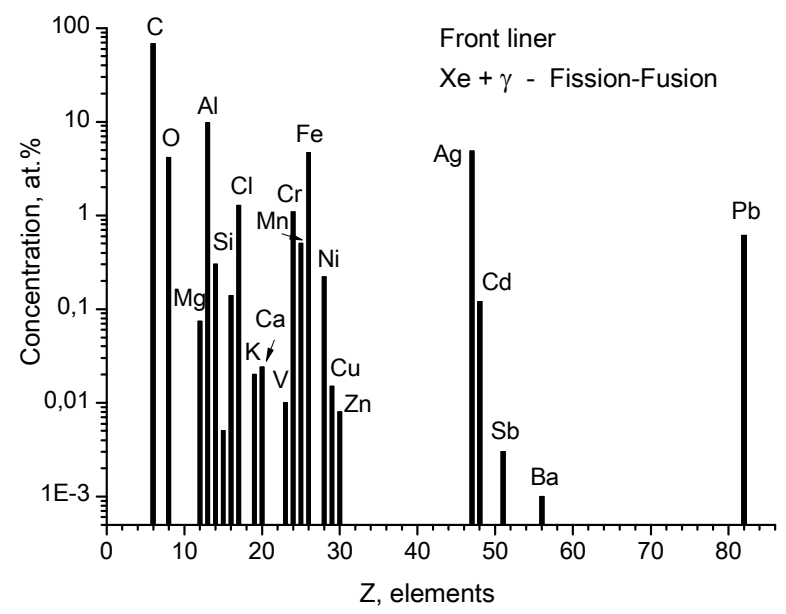

Fig. 11 The averaged element composition for 13 points.

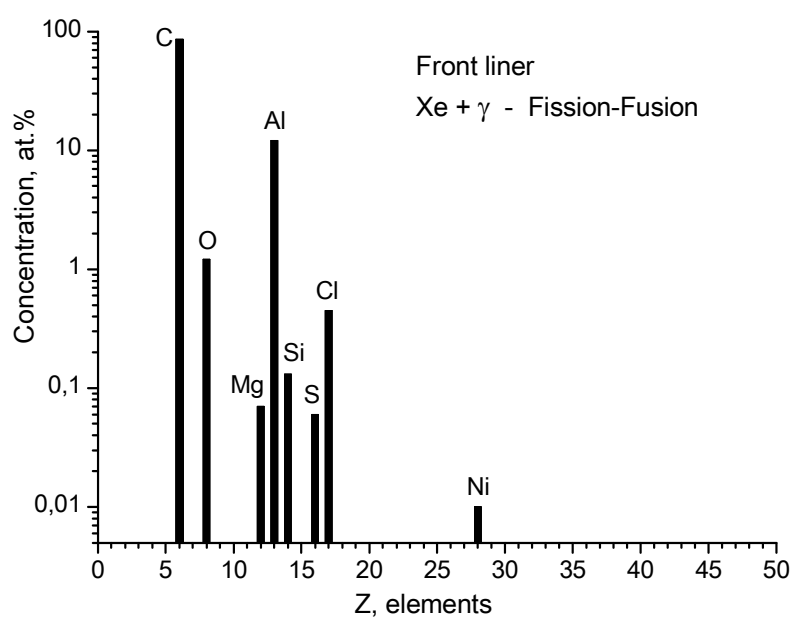

Fig. 13 The averaged element composition for 5 areas.

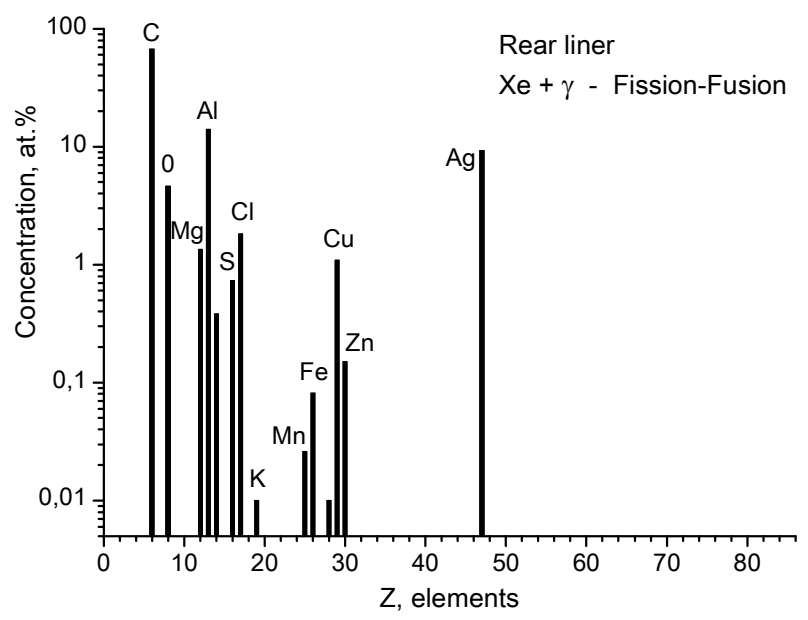

Fig. 12 The averaged element composition for 9 points.

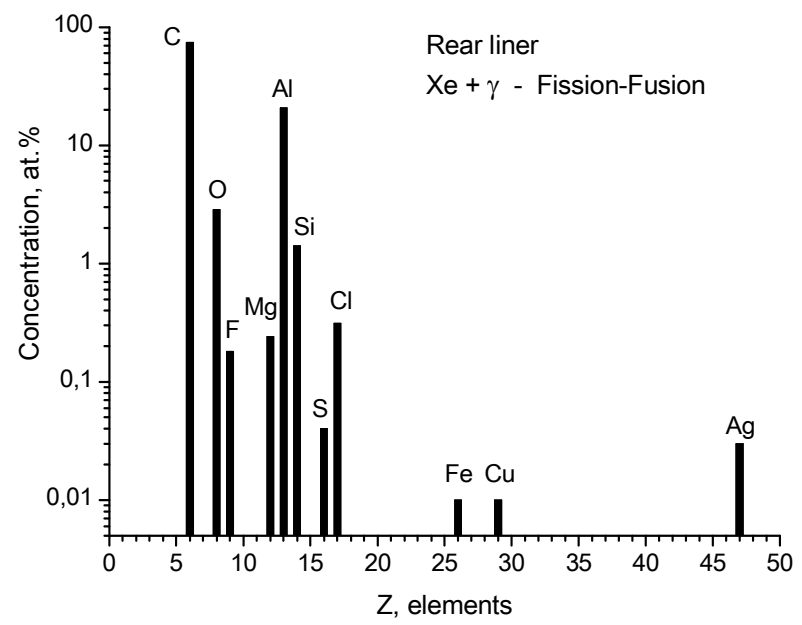

Fig. 14 The averaged element composition for 6 areas. 
large atomic number. b) Measurement at any point is bound by limitations relating to the spatial resolution of measuring equipment.

\section{Summary and Conclusions}

From study above, some results can be known as follows:

(1) Irradiation of xenon was done under the initial pressure 270 bar by braking gamma-rays with $\mathrm{E}_{\max }$ of $10 \mathrm{MeV}$. The chamber pressure dropped to $185 \mathrm{bar}$ which amounts to $\Delta M=M_{P=270}-M_{P=185}=2.2 \mathrm{~g}$.

(2) The surfaces of the high-pressure chamber which had been in contact with xenon were found to be coated with a siskin green layer.

(3) Using the methods of scanning electron microscopy and microprobe roentgen analysis, we observed in the surfaces that had been in contact with xenon and in the particles the following light chemical elements which had not been present previously: ${ }_{9} \mathrm{~F}$, ${ }_{11} \mathrm{Na},{ }_{15} \mathrm{P},{ }_{16} \mathrm{~S},{ }_{17} \mathrm{Cl},{ }_{19} \mathrm{~K},{ }_{20} \mathrm{Ca}$; as well as elements from the group of medium-mass metals: ${ }_{22} \mathrm{Ti},{ }_{23} \mathrm{~V},{ }_{24} \mathrm{Cr}$, ${ }_{25} \mathrm{Mn},{ }_{26} \mathrm{Fe},{ }_{27} \mathrm{Co},{ }_{28} \mathrm{Ni},{ }_{29} \mathrm{Cu},{ }_{30} \mathrm{Zn}$; elements found in the middle of Mendeleev's periodic table: ${ }_{32} \mathrm{Ge},{ }_{38} \mathrm{Sr}$, ${ }_{40} \mathrm{Zr},{ }_{41} \mathrm{Nb},{ }_{42} \mathrm{Mo},{ }_{47} \mathrm{Ag},{ }_{51} \mathrm{Sb},{ }_{56} \mathrm{Ba}$; and such heavy elements as: ${ }_{73} \mathrm{Ta},{ }_{74} \mathrm{~W},{ }_{79} \mathrm{Au},{ }_{81} \mathrm{Tl},{ }_{82} \mathrm{~Pb}$.

(4) At the marked points on the surfaces, the content of some of the elements, especially heavy ones, reaches tens of atomic percent (see the tables).

(5) No differences are observed between the element yields at the front and rear sleeves; however, there is a difference between the front and rear liners.

\section{References}

[1] Didyk, A. Yu., and Wiśniewski, R. 2012. "Nuclear Reactions, Induced by $\gamma$-Quanta, in Palladium Saturated with Deuterium Surrounded by Dense Deuterium Gas." Europhysics Letters 99 (2): 22001.

[2] Didyk, A. Yu., and Wiśniewski, R. 2013. "Nuclear Reactions in Deuterium-Saturated Palladium under Irradiation by $10 \mathrm{MeV} \gamma$-Quanta, in Dense Molecular Deuterium at 1.2 kbar Pressure." Europhysics Letters 103 (4): 42002.

[3] Didyk, A. Yu., Wiśniewski, R. J. 2013. "The Study of Changes in the Element Compositions of $\mathrm{Pd}$ and $\mathrm{Re}$ Specimens Irradiated in Dense Gaseous Deuterium by $\gamma$-Quanta with Boundary Energy up to $23 \mathrm{MeV}$." Journal of Physical Science and Application 3 (4): 209-17.

[4] Didyk, A. Yu., Wiśniewski, R., and Semin, V. 2015. A. JINR preprint R15-2015-87.

[5] Didyk, A. Yu., and Wiśniewski, R. 2015. Phys. Part. Nucl. Lett. 12 (1): 125-44.

[6] Didyk, A. Yu., and Wiśniewski, R. 2015. Phys. Part. Nucl. Lett.12 (1): 145-65; JINR preprint R15-2014-3. Dubna (2014).

[7] Didyk, A. Yu., Wiśniewski, R., and Wilczynska-Kitowska, T. 2015. "The Carbon-Based Structures Synthetized through Nuclear Reaction in Helium at 1.1 kbar Pressure under Irradiation with Braking $\gamma$-Rays of $10 \mathrm{MeV}$ Threshold Energy." Euro Phys. Lett. 109: 22001.

[8] Didyk, A. Yu., Wiśniewski, R., and Wilczynska-Kitowska, T. 2015. "Objects Obtained by $\gamma$ Quanta Irradiation with Threshold Energy of $10 \mathrm{MeV}$ of Pure Gaseous He, under High Pressure, in $\mathrm{CuBe}_{2}$ Apparatus.” J. Phys. Sci. Appl. 5 (4): 268-76.

[9] Didyk, A.Yu., Wiśniewski, R., and Wilczynska-Kitowska, T. 2015. Jour. Surf. Investigation. X-ray, Synchrotron and Neutron Tech. 9 (6): 1218-28.

[10] Didyk, A. Yu. 2015. Phys. and Chem. Material Treatment. 2: 5-19.

[11] Didyk, A. Yu., and Wiśniewski, R. 2013. Phys. Part. Nucl. Lett. 2013. V.10. No. 3 (180): 437-57.

[12] Didyk, A. Yu., Gulbekian, G. G., and Myshinskiy, G. V. 2015. JINR preprint R15-2015-71, Dubna.

[13] Didyk, A. Yu., Gulbekian, G. G., and Myshinskiy, G. V. JINR preprint R15-2015-72, Dubna.

[14] Didyk, A. Yu., Gulbekian, G. G., and Myshinskiy, G. V. 2016. JINR preprint R15-2016-1, Dubna.

PACS 25.20.Dc Proton absorption and scattering

PACS 25.20.De Elastic and inelastic scattering

PACS 25.45.-z H-induced reactions 